\title{
Modelling Pore Blockage of a Wire Mesh by a Water Spray
}

\author{
K. Sidawi ${ }^{\star 1}$, D. J. Bouchard ${ }^{1}$, M. Marengo ${ }^{2}$, S. Chandra ${ }^{1}$ \\ ${ }^{1}$ Department of Mechanical and Industrial Engineering, University of Toronto, Toronto, \\ Canada \\ ${ }^{2}$ Advanced Engineering Centre, School of Computing, Engineering and Mathematics, \\ University of Brighton, Brighton, UK \\ *Corresponding author email: ksidawi@mie.utoronto.ca
}

\begin{abstract}
Water was atomized using a full-cone nozzle and sprayed downwards through a diverter and onto horizontal stainless-steel meshes with nominal pore sizes of 178,457 , or $787 \mu \mathrm{m}$. The mass flow rate of liquid penetrating the mesh was measured continuously using an analytical balance for each pore size. The diverter was used to isolate the central region of the spray and ensure a uniform mass flux. The Sauter mean diameter of the water spray was $\sim 35 \mu \mathrm{m}$. The water spray saturated the horizontal mesh within a few seconds in all cases. It was observed that droplets that landed on the wire mesh quickly coalesced with nearby liquid masses. This caused a delay in the blockage of some pores, as droplets landing near an unblocked pore were leached by neighbouring pools of liquid. The initial transient phase prior to complete blockage of the $178 \mu \mathrm{m}$ pores of the mesh was modelled using a stochastic approach where droplets were assumed to impinge independently and randomly on the wire mesh. To replicate the gradual coverage of the mesh, a correlation was used to account for the increased volume of liquid required to cover a pore based on the number of blocked pores in its Moore neighbourhood. The stochastic model's prediction of mass through the mesh compared well with measured values.
\end{abstract}

\section{Keywords}

Droplet size, mesh, spray, surface coverage, coalescence.

\section{Introduction}

Wire meshes can be used as a sieve to sort material into different size fractions, or to separate liquid and gaseous phases. Mist eliminators, made by layering individual meshes into a stack, are used to remove entrained droplets in a gas stream. One experimental study on mist eliminators showed that the capture efficiency of droplets increases as the wire diameter of the mesh is decreased or as the vapour velocity is increased [1]. To better understand the physical mechanisms of droplet capture by meshes, many authors have studied how individual droplets interact with wires and fibres [2]-[7]. These studies have identified how the impact velocity, impact eccentricity, wire size, wettability, and droplet size all influence how much of the drop is captured by the wire. In most of these studies the drop is usually larger than the wire being contacted.

One of the earlier studies of a spray on a mesh was performed by Hung and Yao [8]. They characterized the four types of dripping that can occur from a mesh. Listed in order of smallest to the largest drops produced:

- wire dripping: drop detaching from a single wire

- corner dripping: drop detaching from where two wires cross

- aperture dripping: drop dripping from the opening formed by four wires

- ceiling dripping: drop dripping from a water film adhered to the underside of the mesh 
When a mesh is positioned under a water spray the droplet distribution is shifted towards larger droplet sizes because the impacting drops coalesce and then drip off the underside of the mesh [9]. On fine meshes the spray can be partially or fully blocked by the water film that forms on the mesh [10]. To study the conditions of when a spray will be blocked by a mesh, a stochastic model is used to predict the transient behaviour of a spray impacting on a mesh before reaching the dripping regime.

\section{Material and Methods}

Experiments were conducted by spraying tap water onto a set of stainless-steel metal meshes used for filtration applications (McMaster-Carr, Aurora, OH, USA). The three meshes used have pore sizes, $D_{\mathrm{p}}$, of 178,457 , and $787 \mu \mathrm{m}$ (product numbers $85385 \mathrm{~T} 98$, 85385T92, and 85385T76, respectively). The wire diameter, $D_{\mathrm{w}}$, of each mesh was 140,140 , and $190 \mu \mathrm{m}$, respectively, resulting in an open area ratio, $r_{0}$, of $31 \%, 59 \%$, and $65 \%$, respectively. The wire meshes were suspended horizontally above an analytical scale (E210, OHAUS Corporation, NJ, USA) that was connected to a laptop for continuous data recording ( $5 \mathrm{~Hz})$, as shown in Fig. $1 \& 2$. Any water from the spray that passed through the mesh was collected by a beaker on the scale and weighed. Experimental observations were repeated 5 times for each mesh size.

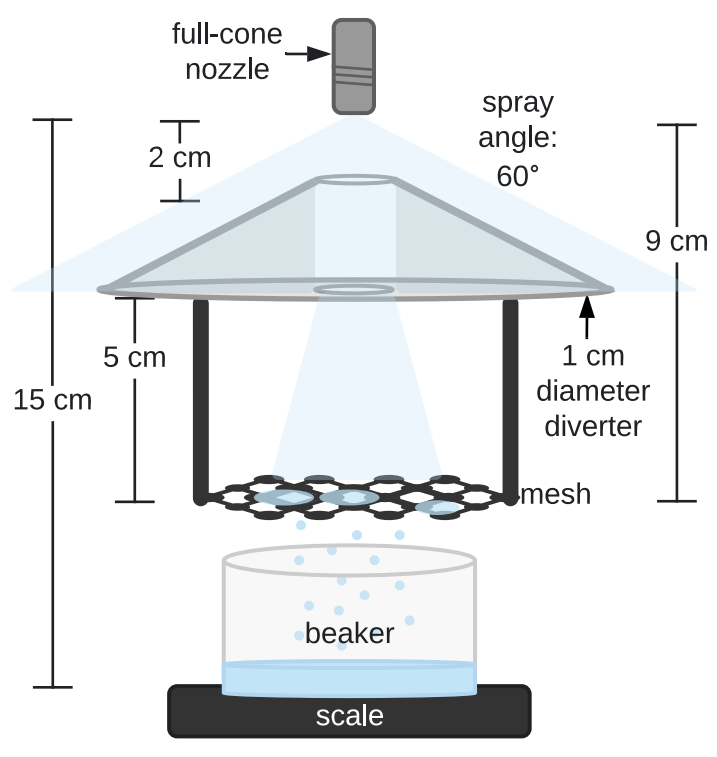

Figure 1. Schematic of a downwards spray though a diverter and mesh. Schematic is NOT to scale.

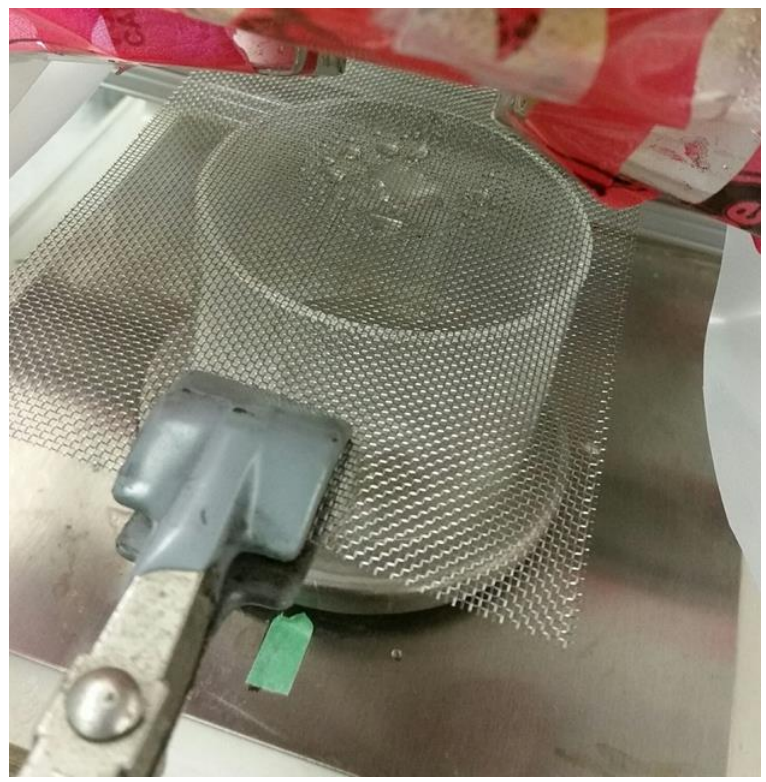

Figure 2. Water entrapped on an $787 \mu \mathrm{m}$ pore mesh. The beaker and scale are visible in the background.

The water spray was generated from a portable air-pressurized spray can (model: M, Sure Shot Milwaukee Sprayer, Menomonee Falls, WI, USA) and a full-cone nozzle (model: 305, Sure Shot Milwaukee Sprayer, Menomonee Falls, WI, USA). The spray can was modified to be connected to a high-pressure compressed air cylinder such that the air pressure in the can remained constant and produced a constant water flow rate. The air pressure in the can was set to $760 \mathrm{kPa}$. The spray angle of the full-cone nozzle was $60^{\circ}$. A custom spray diverter was $3 \mathrm{D}$ printed to reduce the mass flux of the spray that impacts the target mesh; the diverter deflected all the water spray except for water that passed through a $1 \mathrm{~cm}$ diameter aperture at the centre of the spray (see Fig. 1). The distance between the nozzle and the mesh was 9 $\mathrm{cm}$. During data collection, the first three seconds of the spray was blocked to ensure that the 
spray reached steady state and to prevent any large water slugs from impacting the mesh. The spray impact area on the mesh was circular and had a diameter of $\sim 2.5 \mathrm{~cm}$.

The droplet size distribution of the spray was characterised using a DropSizer (DMCH001, MazLite Inc, Toronto, Canada) which consists of a camera and a Class IIlb laser with a wavelength of $905 \mathrm{~nm}$ pulsing at $100 \mathrm{~ns}$. The depth of field is $0.23 \mathrm{~mm}$, while the field of view is $2.82 \times 2.11 \mathrm{~mm}$ with a spatial resolution of $1.1 \mu \mathrm{m} /$ pixel. Images were captured at a position $8 \mathrm{~cm}$ down from the tip of the nozzle with and without a diverter. The droplet size distribution was determined from the captured images using the Canny edge algorithm to identify structures that have strong edges (i.e., in focus). Structures that were not circular such as ligaments or oblong droplets still in the process of breakup were removed if their eccentricity was greater than 0.4 . The area $\left(A_{\mathrm{d}}\right)$ and perimeter $(P)$ of each remaining droplet were measured, and equivalent droplet diameters defined as $4 A_{\mathrm{d}} / P$.

\section{Results and Discussion}

Over 3000 droplets were extracted from images captured of the spray $8 \mathrm{~cm}$ below the nozzle tip and the diverter. The SMD and standard deviation of the spray was $35 \pm 12 \mu \mathrm{m}$, respectively. The SMD of the spray was an order of magnitude smaller than both the mesh pores and the wire diameter.

Fig. 3 shows successive stages, at $0.4 \mathrm{~s}$ intervals of a water spray impinging on a stainlesssteel mesh with a nominal pore size of: (a) 178, (b) 457, and (c) $787 \mu \mathrm{m}$. Images are captured looking down at the mesh at an angle of $27^{\circ}$ below the horizontal using a high-speed camera (Fastcam SA5, Photron, Tokyo, Japan) paired with a telecentric lens (\#59- 839, Edmund Optics, Barrington, New Jersey, USA). In the first column, labelled (a), spray droplets that did not penetrate through the $178 \mu \mathrm{m}$ pore mesh coalesced over it. The small pore size prevented liquid from permeating the mesh, causing water to pool on its surface rather than its underside. The $457 \mu \mathrm{m}$ pores that were covered leached droplets of neighbouring unblocked pores, delaying their blockage. This is especially evident from $1.2 \mathrm{~s} \rightarrow 1.6 \mathrm{~s}$ in Fig. 3b, were droplets on the wire agglomerated with liquid in neighbouring blocked pores. The $787 \mu \mathrm{m}$ pore mesh shown in the third column, labelled (c), exhibited similar trends to the $457 \mu \mathrm{m}$ pore mesh. Liquid entrapped on the 457 and $787 \mu \mathrm{m}$ pore meshes hung from its underside, rather than remain above it as in the $178 \mu \mathrm{m}$ pore mesh.

The cumulative mass per unit area of water collected on a scale after being sprayed downwards through a diverter and a 178,457 , or $787 \mu \mathrm{m}$ pore mesh or unencumbered by a mesh (no mesh) are shown in Fig. 4. The spray impact area on the mesh had a diameter of $\sim 2.5 \mathrm{~cm}$ and this area was used to calculate the area of spray impingement. The mass flux of water impinging on each mesh was constant across all trials and was determined by plotting a regression line through the mass per unit area measurements of the no mesh case at steady state (at $t \geqq 1 \mathrm{~s}$ ). The line's slope represented the mass flux and was equal to $0.0216 \mathrm{~g} / \mathrm{cm}^{2} \mathrm{~s}$, while the $y$-intercept represented the spray force per unit area and was equal to $0.145 \mathrm{~g} / \mathrm{cm}^{2}$. We refer to the impact force of impinging droplets as the "spray force". This force is registered by the scale as mass, but gradually vanishes as the force of impact dissipates. The spray force, $I$, is a summation of the impact force of impinging droplets from the time of impact until it dissipates. At steady state, it reaches the constant value represented by the $y$-intercept. 
(a) $178 \mu \mathrm{m}$

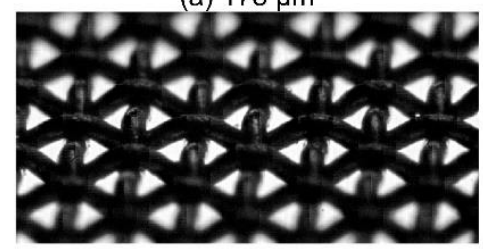

$0.4 \mathrm{~s}$

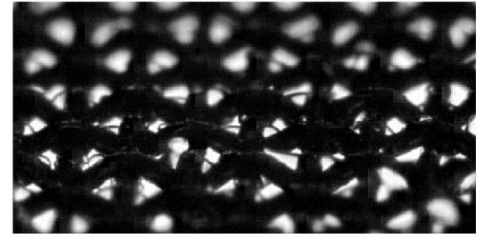

$0.8 \mathrm{~s}$

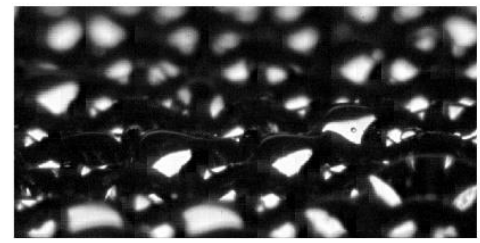

$1.2 \mathrm{~s}$

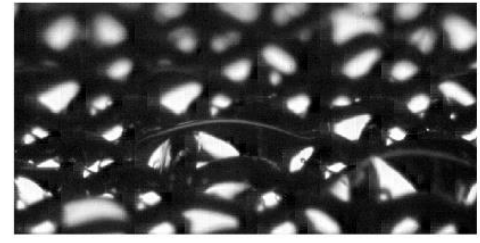

$1.6 \mathrm{~s}$

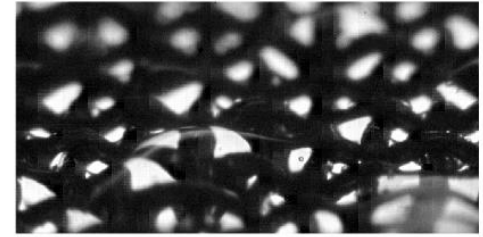

$2.0 \mathrm{~s}$

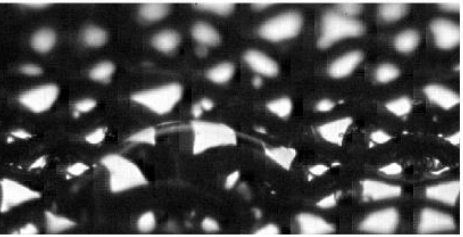

$2.4 \mathrm{~s}$

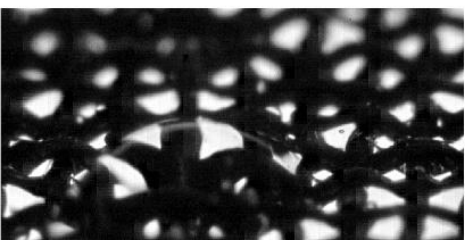

(b) $457 \mu \mathrm{m}$
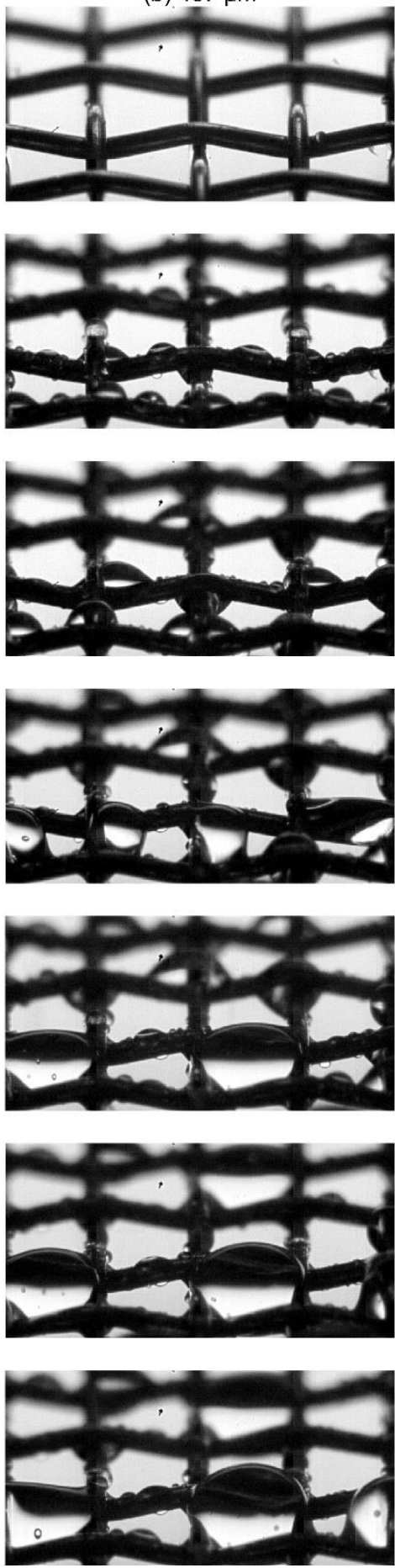

(c) $787 \mu \mathrm{m}$
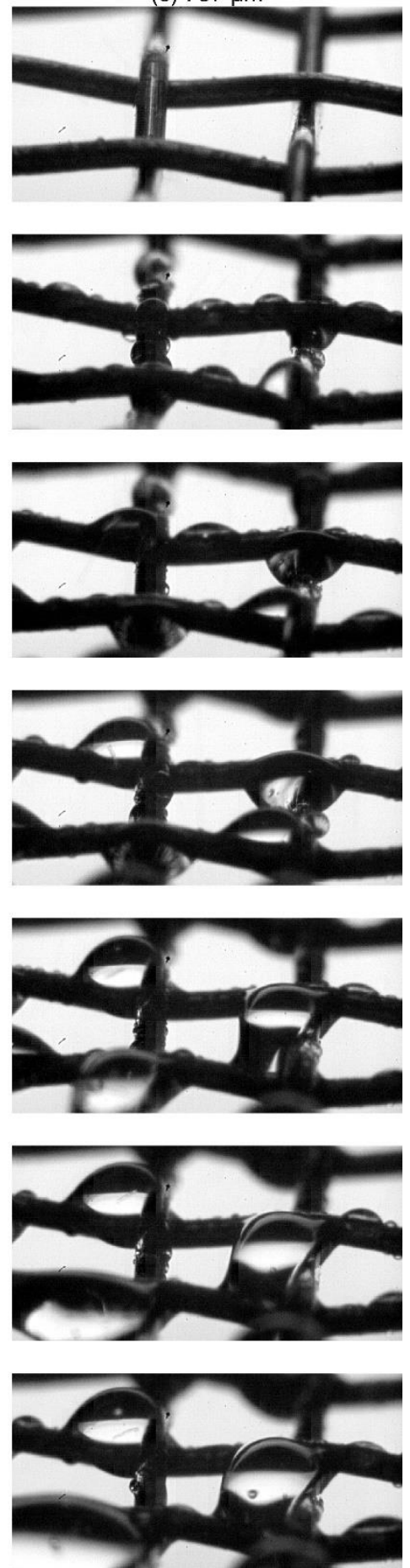

Figure 3. Image sequence at $0.4 \mathrm{~s}$ intervals of a water spray impinging on a stainless-steel mesh with a nominal pore size of: (a) 178, (b) 457, and (c) $787 \mu \mathrm{m}$. The nominal wire diameters are: (a) 140, (b) 140, and (c) $190 \mu \mathrm{m}$, resulting in an open area ratio of (a) 0.31 , (b) 0.59 , and (c) 0.65 , respectively.

In Fig. 4, the 457 and $787 \mu \mathrm{m}$ pore meshes both showed the same initial rapid increase in mass as the no-mesh case due to the cumulative mass per unit area being initially skewed by the disproportionate ratio between spray force, $I$, and droplet mass, $m,(I \gg m)$. However, the rate of increase in mass per unit area decreased rapidly as the mesh's pores were blocked by water. Blockage of the $787 \mu \mathrm{m}$ pore mesh occurred slightly after the $457 \mu \mathrm{m}$ pore mesh, which caused its accumulated mass per unit area to be slightly larger. After their pores were blocked, 
large drops dripped down from the underside of the mesh at regular intervals as water continued to accumulate from to the spray. Both meshes entered the steady dripping regime around the same time and had very similar average mass fluxes. The steady mass flux of water dripping was $\sim 16 \mathrm{mg} / \mathrm{cm}^{2} \mathrm{~s}$ for the 457 and $787 \mu \mathrm{m}$ meshes. Since this mass flux was less than the no mesh mass flux, water was still accumulating on both meshes. For the 178 $\mu \mathrm{m}$ pore mesh case, some water did initially make it through the mesh, but the pores were small enough that they were quickly filled with water. Complete blockage of the pores coupled with their already small size resulted in practically no water penetrating through the $178 \mu \mathrm{m}$ pore mesh. Water droplets did not form and detach from the underside of the mesh since water pooled on top of it. An average mass of $6 \mathrm{mg} / \mathrm{cm}^{2}$ of water penetrated through the 178 $\mu \mathrm{m}$ pore mesh before the spray was blocked, an order of magnitude less than the two larger pore sizes.

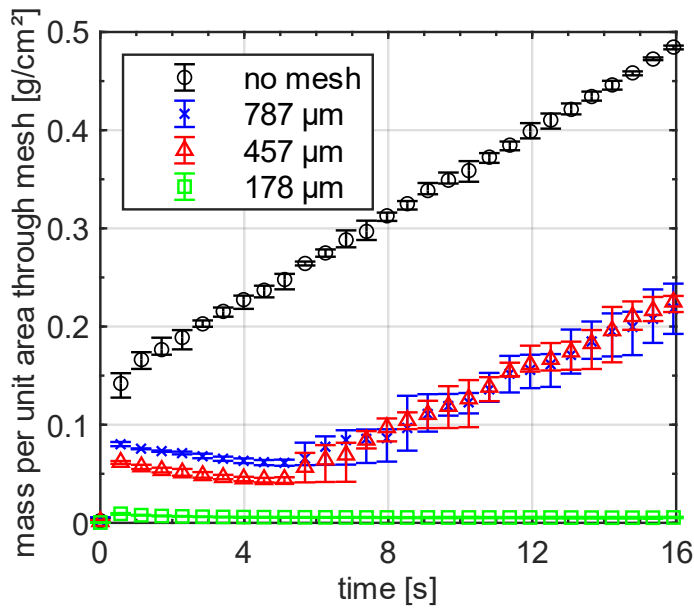

Figure 4. Experimental observations of the mass per unit area of water accumulated on a scale after being sprayed downwards through a divertor and then through 787,457 , and $178 \mu \mathrm{m}$ pore meshes or unencumbered by a mesh (no mesh). A single replicate is shown for each condition.

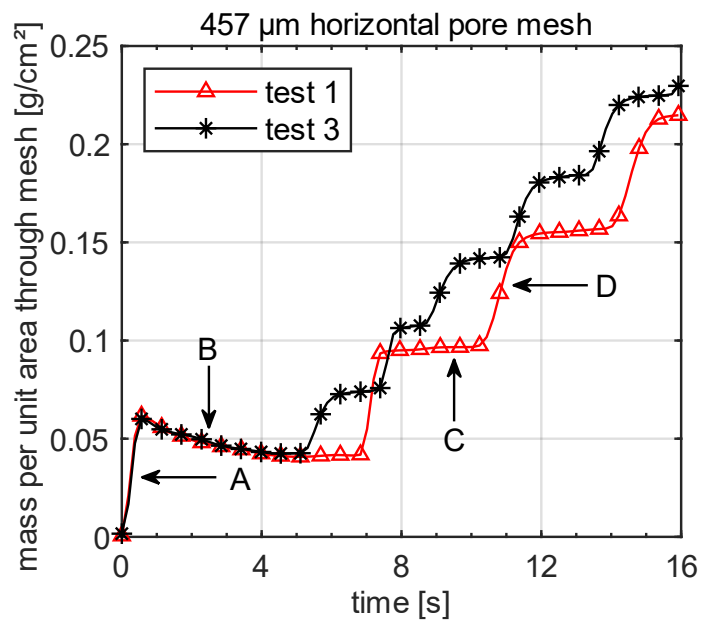

Figure 5. Experimental observations of the mass per unit area of water collected on a scale after being sprayed downwards through a divertor and then through a $457 \mu \mathrm{m}$ pore mesh. Showing 2 of the 5 test replicates.

The mass per unit area of water that accumulated on a scale after being sprayed downwards through a diverter and a $457 \mu \mathrm{m}$ pore mesh is shown in Fig. 5. Two of the five test replicates are shown; the results for each test condition were very similar. Initially (see point A), the scale measured a rapid increase in the mass per unit area of water. However, this is slightly misleading as the scale was also measuring the ephemeral impact force of impinging droplets. The cumulative mass per unit area peaked and then began to decrease at point $B$ as the mesh's pores began to fill with water which prevented some droplets from penetrating through the mesh. Although droplets were still accumulating in the beaker at point B (albeit at a reduced rate), the reduction in the spray force was greater than this mass gain causing the perceived decrease in the measured cumulative mass per unit area. The mass accumulation curve then began to increase in periodic steps as the mass flux through the mesh reached steady state. The vertical portion of the staircase pattern (point C) represents a drop detaching from the liquid film on the underside of the mesh and falling into the beaker. Point $D$ represents the time that water accumulated on the mesh's underside with no drop detachment. Images of the water accumulation above and below each mesh can be seen in [10]. 


\section{Modelling Methodology}

To stochastically model the cumulative mass per unit area of liquid penetrating a mesh, the spray force per droplet must first be defined for the nozzle at the operating conditions. The no mesh case was used to isolate the spray force from the physical mass of droplets. The spray force of a droplet is dictated by the droplet size and by the time elapsed since impact (due to dissipation). Droplet diameters, $D$, were generated by randomly sampling an array of over 3000 measured values. There was no significant difference between the sampled and experimental mean droplet diameters as measured by a two-sample t-test without assuming equal variances. Droplets were assumed to be spherical and their mass equal to $m=\rho \pi D^{3} / 6$. Since the spray force does not instantly vanish after impact, and to account for its gradual dissipation, the spray force at time $t=j / \dot{N}$, was defined as:

$$
I_{\mathrm{j}}=\frac{I_{\mathrm{exp}}^{\prime \prime}}{0.5 \dot{N}} \sum_{\mathrm{i}}^{\mathrm{j}} \frac{m_{\mathrm{i}}}{\bar{m}}\left(1-\frac{t_{\mathrm{i}}}{t_{\mathrm{j}}}\right) \quad \begin{cases}\mathrm{i}=1 & \mid t \leq 1 \\ \mathrm{i}=\mathrm{j}-\dot{N} & \mid t>1\end{cases}
$$

where $I$ is the cumulative spray force at time $t_{\mathrm{j}}, I_{\exp }^{\prime \prime}$ the measured spray force per unit area, $\dot{N}$ the droplet flux, $\bar{m}$ the mean droplet mass, $m$ the droplet mass, $j$ the current droplet index equal to $\dot{N} t$, i the droplet index 1 second prior to $j$ or 1 if $t \leq 1$, and $t$ the time. The initial constant before the summation represents the spray force per droplet averaged over half the mass flux. The half factor and the length of the summation were obtained by fitting the stochastic model to the experimental data (see Fig. 5). The mass ratio accounts for the variation of the spray force based on droplet size. The time ratio accounts for the dissipation of the spray force with time $\left(100 \%\right.$ at $t_{\mathrm{j}}$ reducing linearly over 1 second to $0 \%$ at $\left.t_{\mathrm{j}}-1\right)$. At $t=1$, the spray force per unit area calculated using Eq. 1 is $0.145 \mathrm{~g} / \mathrm{cm}^{2}$, which is equal to the $y$-intercept of the regression line through the experimental data at steady state.
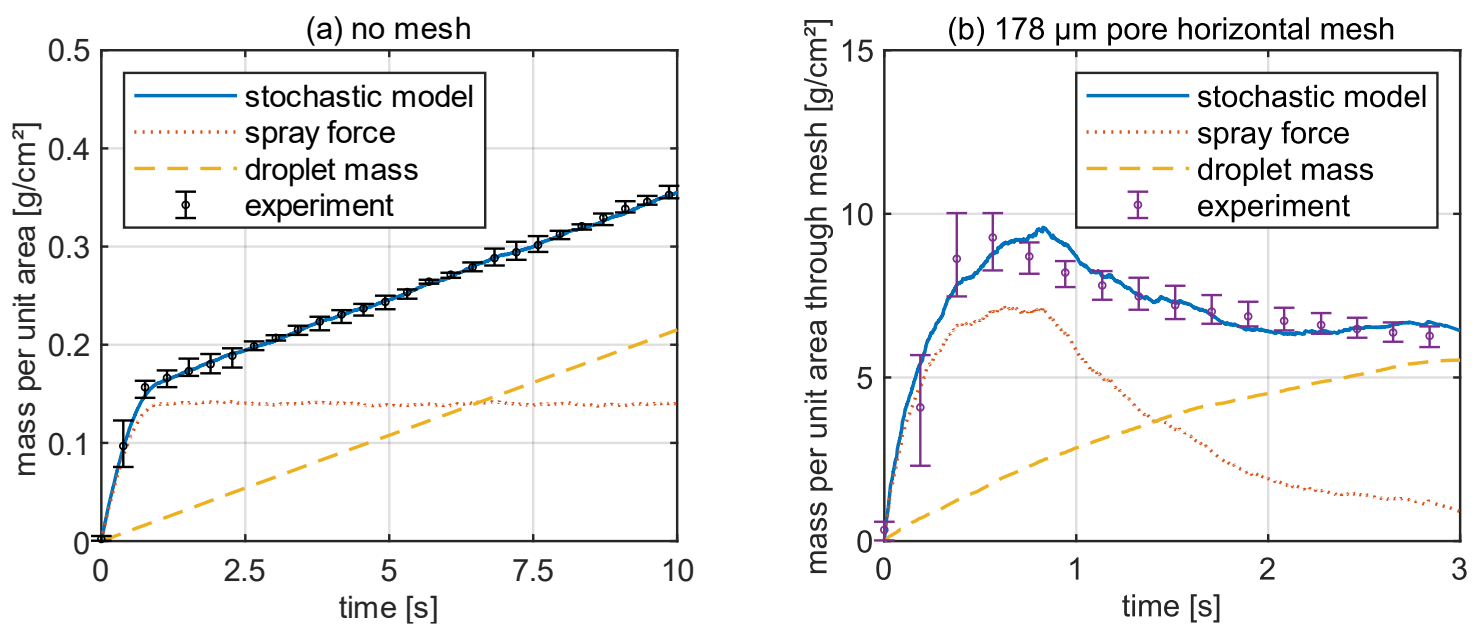

Figure 6. A stochastic model of the mass per unit area of water collected on a scale after being sprayed downwards through a diverter and (a) no-mesh, and (b) a $178 \mu \mathrm{m}$ pore mesh. The stochastic model is the sum of the spray force and the mass of accumulated droplets on the scale. The range of the five experimental trials is shown through error bars.

Fig. 6a shows the measured cumulative mass per unit area of water sprayed downwards through a diverter onto a scale and the stochastic model predicting the mass. The sum of the spray force and cumulative droplet mass per unit area is illustrated as the stochastic model. Initially, the dominant component of the stochastic model is the spray force. The cumulative 
droplet mass per unit area does not exceed the spray force until 6 seconds after initial impact. At steady state $(t \gtrsim 1 \mathrm{~s})$, the slope of a line through the experimental values is equal to the slope of the droplet mass line, i.e. the cumulative mass per unit area of droplets. This validates the model since the mass flux at steady state must be constant. The spray force reaches a constant value at steady state equal to the $y$-intercept value of the regression line. The stochastic model shows good agreement with the experimental measurements, which allows us to use the fitted values in the spray force equation (see Eq. 1) to develop the stochastic model for a $178 \mu \mathrm{m}$ pore mesh.

A stochastic model of a spray in the initial transient phase of blockage of a $178 \mu \mathrm{m}$ pore mesh was developed. It was assumed that droplets generated by the full-cone nozzle impinge independently on the mesh's surface at random locations at a rate equal to the droplet flux [11]. Droplets sizes were generated by randomly sampling an array of over 3000 measured values. The $178 \mu \mathrm{m}$ pore mesh was subdivided into square unit cells that were comprised of half the wire diameter, the pore, and then half the wire diameter across each side. To strike a balance between accuracy and computational time, the stochastic model considered a square consisting of 64-unit cells. Interactions of droplets impinging on a mesh can be broken down into these three rules:

1. No interaction with the mesh; droplets pass through the pores unencumbered and retain their spray force

2. Overlap between the mesh and droplet is less than $30 \%$; the droplet's spray force is absorbed by the mesh, but droplets retain enough momentum to pass through

3. Overlap between the mesh and droplet is more than $30 \%$; droplets are entrapped on the mesh

A pore is blocked once the liquid volume on the wire surrounding it reaches a certain threshold. This threshold for blockage varies based on the number of covered pores in the Moore neighbourhood of the pore in question plus some initial volume. The Moore neighbourhood refers to the 8 cells surrounding a cell in a square lattice. The volume equation (Eq. 2) is obtained by fitting the stochastic model to experimental data shown in Fig. 6b.

$$
V_{\mathrm{k}}=V_{0}\left[r_{\mathrm{o}}^{\left(2-\frac{B}{2}\right)}\right]
$$

where $V_{\mathrm{k}}$ is the volume required to block pore $\mathrm{k}, \mathrm{k}$ the pore index, $V_{0}$ the volume of a pore equal to $V_{0}=D_{\mathrm{p}}^{2} D_{\mathrm{w}}, r_{\mathrm{o}}$ is the ratio of open area, and $B$ the number of blocked pores in the Moore neighbourhood. The resulting stochastic model from the interplay of the three rules and Eq. 2 is presented for a $178 \mu \mathrm{m}$ pore mesh in Fig. 6b. As more pores were blocked, less droplets penetrated the mesh and the spray force approached 0 . Unlike the no mesh case (see Fig. 6a), the $178 \mu \mathrm{m}$ pore mesh prevented $75 \%$ of droplets from reaching the scale even before any pores were blocked.

\section{Conclusion}

An approach is presented to model a spray's impingement on a mesh in the initial stages while pores are still not fully blocked. Images captured of a spray impinging on a mesh showed that droplets move towards and coalesce with larger liquid masses on the mesh's surface. 
Furthermore, a significant portion of the initial mass measured by a scale under a mesh while water is sprayed through it is due to the impact force of impinging droplets. A good approximation of the spray force was determined by fitting a stochastic model of the cumulative mass per unit area of the no mesh case to the experimental observations. After imposing some rules, a stochastic model showed good agreement with the experimental results of the cumulative mass per unit area of the water that penetrated through a $178 \mu \mathrm{m}$ pore mesh. The volume required to cover a given pore was found to increase if pores in the Moore neighbourhood were blocked.

\section{Nomenclature}

$\begin{array}{llll}A & \text { droplet area }\left[\mu \mathrm{m}^{2}\right] & \mathrm{j} & \text { final index of summation } \\ B & \text { number of blocked pores in the Moore neighbourhood } & \mathrm{k} & \text { pore index } \\ D & \text { droplet diameter }[\mu \mathrm{m}] & m & \text { droplet mass }[\mathrm{g}] \\ D_{\mathrm{p}} & \text { pore size }[\mu \mathrm{m}] & \dot{N} & \text { droplet flux }\left[\mathrm{droplet} \mathrm{cm}^{-2} \mathrm{~s}^{-1}\right] \\ D_{\mathrm{w}} & \text { wire diameter }[\mu \mathrm{m}] & P & \text { droplet perimeter }[\mu \mathrm{m}] \\ I & \text { spray force }[\mathrm{g}] & r_{0} & \text { ratio of open area of mesh } \\ I_{\text {exp }}^{\prime \prime} & \text { measured spray force per unit area }\left[\mathrm{g} \mathrm{cm}^{-2}\right] & t & \text { time }[\mathrm{s}] \\ \mathrm{i} & \text { initial index of summation } & V & \text { threshold pore volume }\left[\mu \mathrm{m}^{3}\right]\end{array}$

\section{References}

[1] H. T. El-Dessouky, I. M. Alatiqi, H. M. Ettouney, and N. S. Al-Deffeeri, "Performance of wire mesh mist eliminator," Chem. Eng. Process. Process Intensif., vol. 39, no. 2, pp. 129-139, 2000, doi: https://doi.org/10.1016/S0255-2701(99)00033-1.

[2] L. S. Hung and S. C. Yao, "Experimental investigation of the impaction of water droplets on cylindrical objects," Int. J. Multiph. Flow, vol. 25, no. 8, pp. 1545-1559, 1999, doi: https://doi.org/10.1016/S0301-9322(98)00085-8.

[3] E. Lorenceau, C. Clanet, D. Quéré, and M. Vignes-Adler, "Off-centre impact on a horizontal fibre," Eur. Phys. J. Spec. Top., vol. 166, no. 1, pp. 3-6, 2009, doi: 10.1140/epjst/e2009-00868-0.

[4] K. Piroird, C. Clanet, É. Lorenceau, and D. Quéré, "Drops impacting inclined fibers," J. Colloid Interface Sci., vol. 334, no. 1, pp. 70-74, 2009, doi: https://doi.org/10.1016/j.jcis.2009.03.004.

[5] E. Sher, L. F. Haim, and I. Sher, "Off-centered impact of water droplets on a thin horizontal wire," Int. J. Multiph. Flow, vol. 54, pp. 55-60, 2013, doi: https://doi.org/10.1016/j.ijmultiphaseflow.2013.03.002.

[6] S.-G. Kim and W. Kim, "Drop impact on a fiber," Phys. Fluids, vol. 28, no. 4, p. 42001, 2016, doi: 10.1063/1.4945103.

[7] M. Safavi and S. S. Nourazar, "Experimental, analytical, and numerical study of droplet impact on a horizontal fiber," Int. J. Multiph. Flow, vol. 113, pp. 316-324, 2019, doi: https://doi.org/10.1016/j.jmultiphaseflow.2018.10.018.

[8] L. S. Hung and S. C. Yao, "Dripping phenomena of water droplets impacted on horizontal wire screens," Int. J. Multiph. Flow, vol. 28, no. 1, pp. 93-104, 2002, doi: https://doi.org/10.1016/S0301-9322(01)00061-1.

[9] S. C. P. Carvalho, J. L. M. P. de Lima, and M. I. P. de Lima, "Increasing the Rainfall Kinetic Energy of Spray Nozzles by using Meshes," L. Degrad. Dev., vol. 27, no. 4, pp. 1295-1302, 2016, doi: https://doi.org/10.1002/ldr.2349.

[10] C. Boscariol, D. J. Bouchard, M. Gibbons, M. Marengo, and S. Chandra, "Spray Impact on Metallic Meshes," in 29th European Conference on Liquid Atomization and Spray Systems, 2019, pp. 2-4.

[11] K. Sidawi, P. Moroz, and S. Chandra, "On surface area coverage by an electrostatic rotating bell atomizer," J. Coatings Technol. Res., 2021, doi: 10.1007/s11998-020-004304. 